\title{
Genomic analysis of claw lesions in Holstein cows: Opportunities for genomic selection, quantitative trait locus detection, and gene identification
}

\author{
Iola Croué, ${ }^{1,2,3 *}$ Alexis Michenet, ${ }^{1}$ Hélène Leclerc, ${ }^{3}$ and Vincent Ducrocq ${ }^{2}$ \\ ${ }^{1}$ ALLICE, F-78350 Jouy-en-Josas, France \\ ${ }^{2}$ INRA, AgroParisTech, Université Paris Saclay, F-78350 Jouy-en-Josas, France \\ ${ }^{3}$ Institut de l'Elevage, F-78350 Jouy-en-Josas, France
}

\section{ABSTRACT}

Claw lesions are the third most important health issue in dairy cattle, after mastitis and reproductive disorders, and genomic selection is a key component for long-term improvement of claw health. The objectives of this study were to assess the feasibility of a genomic evaluation for claw health in French Holstein cows, explore possibilities to increase evaluation accuracy, and gain a better understanding of the genetic determinism of claw health traits. The data set consisted of 48,685 trimmed Holstein cows, including 9,646 that were genotyped; 478 genotyped sires were also used. Seven claw lesion traits were evaluated using BLUP, genomic BLUP, BayesC, and single-step genomic BLUP, and the accuracies obtained using these approaches were measured through a validation study. The BayesC approach was used to detect quantitative trait locus (QTL) regions associated with the 7 individual traits (digital dermatitis, heel horn erosion, interdigital hyperplasia, sole hemorrhage circumscribed, sole hemorrhage diffused, sole ulcer, and white line fissure) based on their Bayes factor. Annotated genes on these regions were reported. Genomic evaluation approaches generally did not allow for greater accuracies than BLUP, except for single-step genomic BLUP. Accuracies were moderate, but best and worst validation animals were correctly discriminated and showed significant differences in lesion frequencies. A total of 192 QTL regions were identified, including 13 with major evidence or involved for 2 of the traits. A high number of genes were present on these regions, and several had functions associated with the immune system. In particular, the $E P Y C$ gene is located close to a major evidence QTL for resistance to digital dermatitis that is also a QTL for interdigital hy-

Received November 12, 2018

Accepted March 19, 2019.

*Corresponding author: iola.croue@inra.fr perplasia (on chromosome 5, around 20.9 MB) and has been associated with Ehlers-Danlos syndrome in cattle. Genomic selection can be used to improve resistance to individual claw lesions, and several possibilities exist to improve accuracies of genomic evaluations.

Key words: genomic evaluation, claw health, dairy cattle, quantitative trait loci

\section{INTRODUCTION}

Claw lesions are an issue in terms of both welfare (Bruijnis et al., 2012) and profitability. They are ranked third in cost among health disorders in dairy cattle, after mastitis and reproductive disorders (Enting et al., 1997), mainly due to treatment costs, reduced milk production, discarded milk, increased calving interval, and increased involuntary culling (Bruijnis et al., 2010; Charfeddine and Pérez-Cabal, 2017). Furthermore, claw lesions usually have quite high frequencies (Enting et al., 1997; van der Waaij et al., 2005; Charfeddine and Pérez-Cabal, 2017). In France, the proportion of trimmed cows with at least one lesion goes up to $82 \%$ (Croué et al., 2017).

Hence, it is crucial to reduce the frequency of claw lesions. Although heritabilities are often found to be very low (Heringstad et al., 2018), most studies conclude that there is enough genetic variability of claw health traits for genetic selection to occur and genetic selection is a key component for long-term improvement of claw health. This is why a few countries implemented genetic evaluations of claw health traits in recent years (Stoop et al., 2010; Johansson et al., 2011; Jamrozic et al., 2017) and others have ongoing projects with this goal (Gernand et al., 2012; Charfeddine and PérezCabal, 2017). In France, a private company (EVOLUTION) has led a project for implementation of genetic evaluation of Holstein cows; the evaluation was released in autumn 2017 (EVOLUTION, 2017).

In addition to low heritabilities, claw health traits are generally difficult to measure and many sires only have 
a few number of daughters with records. Furthermore, in most cases, the start of data collection is recent, hence no historical data are available (Heringstad et al., 2018). In the context of dairy breeds with routine genomic evaluations for other traits, genomic selection is both needed and a challenge for these new traits.

The objectives of the present study were to assess the feasibility of a genomic evaluation for claw health in French Holstein cows, to explore possibilities to gain in accuracy, and to increase our knowledge on the genetic determinism of claw health traits.

\section{MATERIALS AND METHODS}

\section{Data}

The phenotypes used in this study were collected on French Holstein cows from April 2014 to December 2017, by claw trimmers trained with a unique protocol (France Génétique Elevage, 2013). These claw trimmers recorded observed claw lesions as they performed routine trimming in herds. Data were eliminated using the steps described in Croué et al. (2017), and minimal requirements of 100 cows trimmed per trimmer $\times$ year and 25 daughters per sire were added. Because most of the cows (86\%) only had one record, only the first trimming information was considered for cows with multiple records.

The current study takes into account the phenotypes from 48,685 trimmed cows. Pedigree was traced back for 3 generations and includes 119,978 animals.

\section{Traits}

The traits considered are lesion traits with a binary definition: they were recorded as 1 if the trimmer observed the lesion during trimming and 0 if she did not. The lesions considered are digital dermatitis (DD), heel horn erosion (HHE), interdigital hyperplasia (IH), sole hemorrhage circumscribed (SHC), sole hemorrhage diffused (SHD), sole ulcer (SU), and white line fissure (WLF), with which white line abscess and double sole were grouped. These traits are mainly defined according to the International Committee for Animal Recording atlas (International Committee for Animal Recording, 2015) with some limited differences, as reported in Croué et al. (2017).

\section{Genotypes}

Genotypes were extracted from the French genomic database for cattle. Animals were genotyped (or imputed from low-density genotypes) on the Illumina Bo- vine SNP50 BeadChip. Quality control was performed within breed. Genotyped animals with a call rate below 0.95 were removed from the analysis. The SNP showing departure from Hardy-Weinberg equilibrium $(P<$ 0.0001 ) or with more than $10 \%$ missing genotypes were removed. Parent-progeny compatibility was verified and incompatible animals were eliminated. In the end, 43,801 SNP were used. For QTL detection, the custom part of the Illumina SNP50 BeadChip and EuroG10K was also considered, increasing the number of SNP used to 51,630. The supplementary SNP are specific SNP added on the chips for research purposes, with generally good annotations, and hence they are particularly interesting to study annotated genes on a specific region or the study of genetic defects. A total of 9,646 phenotyped cows and 478 sires had genotypes available. These sires had on average 102 daughters with phenotypes (25 to 1,225$)$.

\section{Evaluation Approaches}

Three genomic evaluation approaches were considered and compared with a conventional BLUP: 2 2-step genomic methods, genomic BLUP (GBLUP; VanRaden, 2008) and BayesC (Habier et al., 2011), and single-step GBLUP (SSGBLUP; Misztal et al., 2009; Christensen and Lund, 2010), which combines pedigree and genomic information.

The BLUP and SSGBLUP were applied to the following single-trait animal model:

$$
y_{i j k}=\mu+h v_{i}+p s_{j}+a_{k}+\varepsilon_{i j k},
$$

where $y_{i j k}$ is the observed phenotype for $\mathrm{DD}, \mathrm{HHE}, \mathrm{IH}$, $\mathrm{SHC}, \mathrm{SHD}, \mathrm{SU}$, or WLF; $\mu$ is the general mean; $h v_{i}$ is the herd-date of visit contemporary group; $p s_{j}$ is the effect of parity $\times$ lactation stage $(1-50,51-100,101-150$, 151-200, 201-250, 251-300, 301-350, 351-400, and $401-550 \mathrm{~d}) ; a_{k}$ is the additive genetic value of the animal treated as a random effect with a variance-covariance matrix proportional to the relationship matrix; and $\varepsilon_{i j k}$ is a random residual, accounting for heterogeneous residual variances depending on a random trimmer $x$ year effect. These heterogeneous residual variances were included in the model in the form of different weights given to records depending on the trimmer and year of trimming, estimated simultaneously with the effects in the model.

Single-step GBLUP is similar to a pedigree-based evaluation, with a relationship matrix combining pedigree and genomic information. The resulting inverse of the relationship matrix, $\mathbf{H}^{-\mathbf{1}}$, is defined as (Aguilar et al., 2010): 


$$
\mathbf{H}^{-1}=\mathbf{A}^{-1}+\left(\begin{array}{cc}
0 & 0 \\
0 & \mathbf{G}^{*-1}-\mathbf{A}_{22}{ }^{-1}
\end{array}\right),
$$

where $\mathbf{A}^{-1}$ is the inverse of the pedigree relationship matrix, $\mathbf{A}_{22}{ }^{-1}$ is the inverse of the pedigree relationship matrix among genotyped animals, $\mathbf{G}^{*-1}$ is the inverse of the genomic relationship matrix $\mathbf{G}^{*}\left(\mathbf{G}^{*}=0.95 \mathbf{G}+\right.$ $0.05 \mathbf{A}_{22}$ ), with $\mathbf{G}$ constructed as in VanRaden (2008). $\mathbf{G}^{*}$ is scaled to $\mathbf{A}_{22}$, such that the means of the diagonal and off-diagonal elements of $\mathbf{G}^{*}$ equal the means of the diagonal and off-diagonal elements of $\mathbf{A}_{22}$, respectively.

Pre-adjusted performances were calculated from the BLUP official evaluation for these traits, in a multitrait context, for all individuals with a phenotype. For this step, cows sired by bulls with less than 25 daughters were also included and contemporary nontrimmed cows were considered, through the use of a "trimming status" trait as in scenario (3) of (Croué et al., 2017), using the model described in the present study for BLUP and SSGBLUP. For genomic approaches, these pre-adjusted performances were used to compute phenotypes for genotyped individuals. Phenotypes were either directly pre-adjusted performances (yield deviation; YD) for genotyped cows, or daughter yield deviations (DYD) for genotyped sires: the pre-adjusted performances of their nongenotyped daughters were corrected for their dam's EBV and summarized into average progeny preadjusted performances. Both GBLUP and BayesC were run in a single-trait context for genotyped animals and their ancestors only. Both methods used YD and DYD as phenotypic records, weighted by their equivalent number of performances.

The BayesC and GBLUP approaches considered that part of the total genetic variance was represented by a residual polygenic effect; this part was estimated during the analysis. For BayesC, a fixed proportion $\pi$ of $1 \%$ of the total SNP was considered to have an effect on the traits.

The BLUP and SSGBLUP were performed using the BLUPF90 software (Misztal, 2008) and GBLUP and BayesC using the GS3 software (Legarra et al., 2014).

The (co)variance components used for the present study were those estimated in Croué et al. (2017). Heritability estimates were very low to low: 0.02 for SHC and SHD, 0.05 for HHE and SU, 0.06 for WLF, and 0.09 for DD and IH.

\section{Validation Study}

To assess the predictive ability of the different evaluation approaches considered, a cross-validation study was implemented: all phenotypes collected on cows born after November 2013 were not considered in the analyses, so that the $20 \%$ youngest genotyped animals had their phenotypes removed. These 2,025 cows were used as a validation population and mimicked young candidates to selection. On this validation population, 2 validation criteria were considered. Accuracy was assessed as the correlation between EBV and YD, divided by the square root of the heritability of the trait. Evaluation bias was assessed through the regression coefficient of YD on EBV. The closer the regression coefficient was to 1 , the less biased the evaluation. Standard errors of bias and accuracy were estimated using bootstrap with 1,000 samples.

To further assess the ability to correctly rank selection candidates, the validation population was divided in 5 groups of equal size based on EBV, and the correlation between mean EBV and mean YD within group was calculated over the 5 groups. In addition, lesion frequencies in the best and worst groups were compared and a $t$-test was realized to determine whether the observed frequencies were significantly different.

\section{QTL Detection}

Phenotypes for QTL detection were YD and DYD, as described above, weighted according to their equivalent number of performances, using the whole reference population, including phenotypes of the validation population. A BayesC approach was used, assuming that 1\% of the SNP had an effect at each iteration (i.e., 516 SNP were selected at each iteration). These SNP were assumed to capture all of the genetic variance.

The Bayes factor (BF; Schurink et al., 2012) was used to assess the degree of association between each SNP and the traits. The BF is defined as (Kass and Raftery, 1995):

$$
\mathrm{BF}=\frac{P_{i} / 1-P_{i}}{\pi / 1-\pi},
$$

where $P_{i}$ is the probability for the SNP to have a nonzero effect and $\pi$ is the proportion of SNP having a nonzero effect. The Bayes factor is the criterion recommended for QTL detection when using Bayesian methods (Wakefield, 2009; Legarra et al., 2015).

The $\mathrm{BF}$ was transformed into $2 \log \mathrm{BF}$ to gain clarity for visual appraisal of QTL. The SNP were regrouped in QTL regions as described in Michenet et al. (2016): QTL regions were identified around SNP having a 2log$\mathrm{BF} \geq 6$ (strong evidence). The SNP with $2 \log \mathrm{BF} \geq 2$ (positive evidence) located close to the peak SNP were included in the QTL region when they were within a sliding window of $0.5 \mathrm{Mb}$ of the peak SNP. The window 
Table 1. Lesion frequencies in the whole population, genotyped individuals, and validation individuals

\begin{tabular}{lccc}
\hline Trait & $\begin{array}{c}\text { Whole } \\
\text { population }\end{array}$ & $\begin{array}{c}\text { Genotyped } \\
\text { individuals }\end{array}$ & $\begin{array}{c}\text { Validation } \\
\text { population }\end{array}$ \\
\hline Digital dermatitis & 0.30 & 0.26 & 0.25 \\
Heel horn erosion & 0.39 & 0.37 & 0.32 \\
Interdigital hyperplasia & 0.08 & 0.07 & 0.04 \\
Sole hemorrhage circumscribed & 0.13 & 0.13 & 0.18 \\
Sole hemorrhage diffused & 0.32 & 0.32 & 0.33 \\
Sole ulcer & 0.07 & 0.06 & 0.06 \\
White line fissure & 0.12 & 0.10 & 0.08 \\
\hline
\end{tabular}

was slid when at least one SNP with $2 \log B F \geq 2$ was integrated in the QTL region. The $2 \operatorname{logBF}$ thresholds of significance were selected, as proposed by Kass and Raftery (1995).

Candidate genes associated with either major evidence QTL $(2 \log B F \geq 10)$ or overlapping QTL regions for 2 of the traits were identified from the Ensembl database, using Biomart (http://www.ensembl.org/biomart/ martview). Genes were selected when they were located within $500 \mathrm{~kb}$ of the identified QTL regions. Mouse Genome Informatics (http://www.informatics.jax.org/) was then used to check the functions associated with each selected gene.

\section{RESULTS}

\section{Lesion Frequencies}

Lesion frequencies were generally high for HHE, DD, and SHD (Table 1). In general, genotyped individuals had lesion frequencies similar to or slightly lower than those of the whole population. The validation population (youngest genotyped animals) had generally slightly lower frequencies, except for SHC.

\section{Genomic Evaluation}

For all evaluation approaches, low to moderate accuracies were observed (Table 2). Regression coefficients varied widely depending on the trait and evaluation approach. Standard errors were high, making the comparison between approaches difficult. Generally, genomic approaches allowed for slightly higher accuracies than BLUP. However, the difference was not significant for most of the traits. For the traits where these differences were significant (more than $1 \mathrm{SE}$ difference between the 2 values), SSGBLUP was the approach allowing for the highest accuracy.

When grouping cows of the validation population into 5 groups depending on their EBV estimated using a SSGBLUP evaluation approach, we observed that, even for the traits with the lowest accuracy, the best and worst groups of animals were generally well discriminated (Figures 1 and 2). The best and worst groups based on EBV always corresponded to animals with on average good and bad preadjusted performances, respectively, although not all of the intermediary groups were properly ranked. For the traits with higher accuracy, group ranking was relevant for all groups (Figure 2).

The difference in lesion frequency among the worst and best groups were significant (with a first-order error of $10 \%$ ) for all approaches and traits, except for SHC for all approaches and HHE when using BLUP (Table 3). Genomic approaches generally allowed for proper ranking of validation animals: validation animals with better EBV tended to be the less affected ones. For all traits, SSGBLUP was the approach allowing for the

Table 2. Accuracies (Acc.) and slopes of the regression of EBV on yield deviation for BLUP, genomic BLUP (GBLUP), BayesC, and single-step GBLUP (SSGBLUP), with SE in parentheses

\begin{tabular}{|c|c|c|c|c|c|c|c|c|}
\hline Trait $^{1}$ & \multicolumn{2}{|c|}{ BLUP } & \multicolumn{2}{|c|}{ GBLUP } & \multicolumn{2}{|c|}{ BayesC } & \multicolumn{2}{|c|}{ SSGBLUP } \\
\hline HHE & $0.28(0.11)$ & $0.88(0.34)$ & $0.42(0.11)$ & $0.80(0.20)$ & $0.39(0.11)$ & $0.55(0.15)$ & $0.51(0.10)$ & $1.11(0.23)$ \\
\hline $\mathrm{IH}$ & $0.30(0.08)$ & $0.66(0.19)$ & $0.28(0.08)$ & $0.39(0.11)$ & $0.20(0.08)$ & $0.38(0.12)$ & $0.26(0.08)$ & $0.38(0.12)$ \\
\hline SHC & $0.25(0.14)$ & $1.07(0.61)$ & $0.29(0.14)$ & $0.84(0.41)$ & $0.31(0.14)$ & $0.50(0.23)$ & $0.28(0.14)$ & $0.78(0.40)$ \\
\hline SHD & $0.70(0.13)$ & $3.07(0.59)$ & $0.49(0.13)$ & $1.44(0.39)$ & $0.39(0.14)$ & $0.69(0.25)$ & $0.63(0.14)$ & $1.87(0.41)$ \\
\hline
\end{tabular}

${ }^{1} \mathrm{DD}=$ digital dermatitis; HHE = heel horn erosion; $\mathrm{IH}=$ interdigital hyperplasia; $\mathrm{SHC}=$ sole hemorrhage circumscribed; SHD $=$ sole hemorrhage diffused; $\mathrm{SU}=$ sole ulcer; $\mathrm{WLF}=$ white line fissure. 
Sole hemorrhage circumscribed

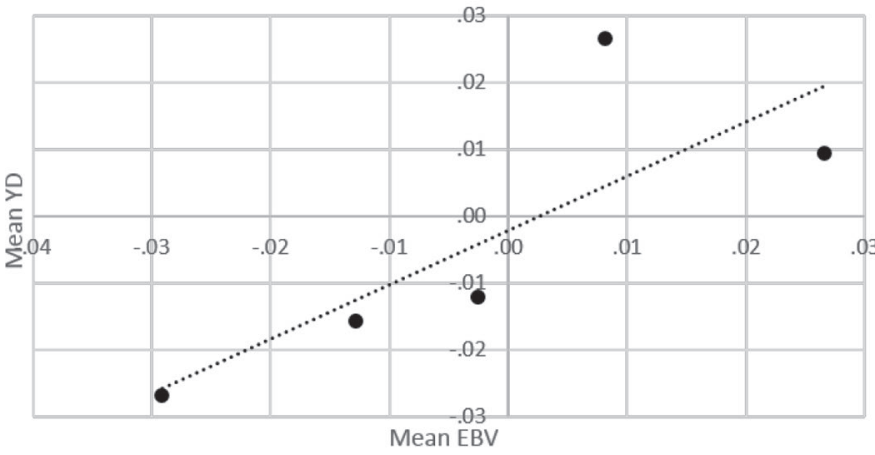

Interdigital hyperplasia

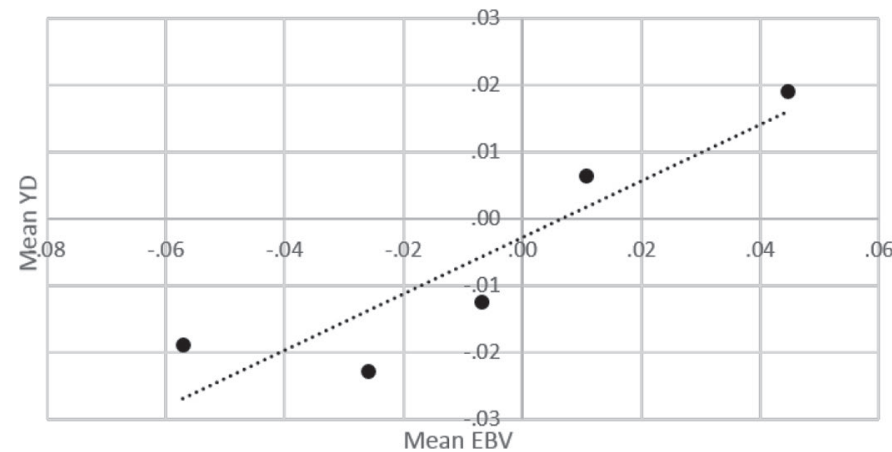

Figure 1. Regression of mean yield deviation (YD) on mean EBV among 5 groups of validation animals, created according to their EBV, for the 2 traits with the lowest accuracy, using a single-step genomic BLUP (SSGBLUP) evaluation approach.

highest level of significance and hence the most consistent distinction between best and worst animals in terms of lesion frequencies.

\section{QTL Detection}

In total, 192 strong evidence QTL $(2 \log B F \geq 6)$ were identified for the 7 lesion traits. Detailed information (position of peak, 2logBF of peak, beginning, and end of the QTL region) can be found for all QTL in Appendix Table A1. Quantitative trait loci were identified
White line fissure

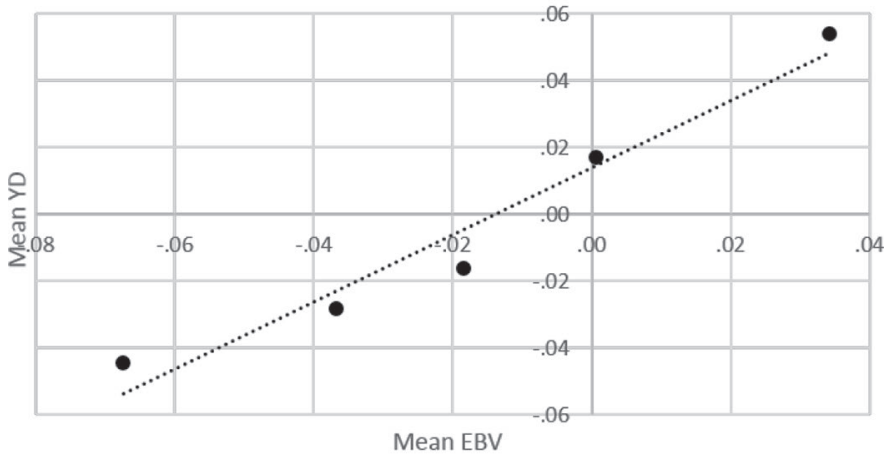

Sole hemorrhage diffused

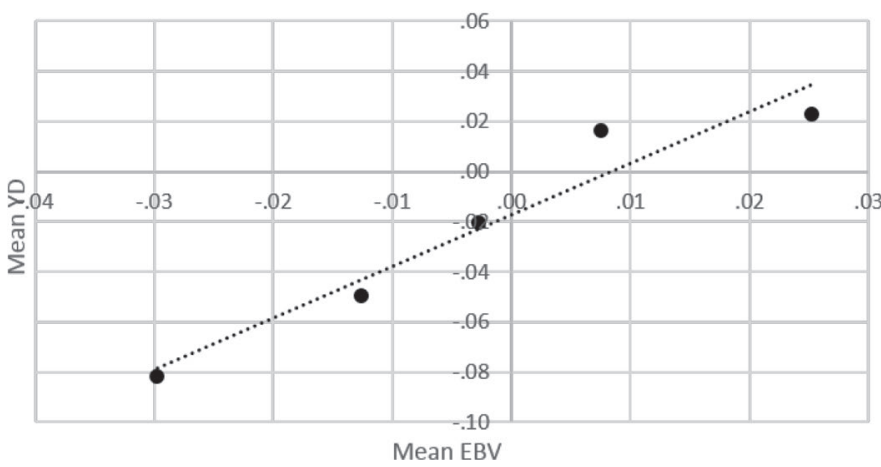

Figure 2. Regression of mean yield deviation (YD) on mean EBV among 5 groups of validation animals, created according to their EBV, for the 2 traits with the highest accuracy, using a single-step genomic BLUP (SSGBLUP) evaluation approach.

for all traits: 41 were found for DD, 24 for HHE, 49 for IH, 9 for SHC, 7 for SHD, 27 for SU, and 35 for WLF. These QTL were spread all over the genome, with 1 to 11 QTL per chromosome for all traits. The QTL region sizes were on average 1.277 MB wide, ranging from a single SNP to $2.598 \mathrm{MB}$ (for $\mathrm{SU}$ ).

Eight of the QTL had major evidence $(2 \log B F \geq 10)$ : 4 for IH, 2 for DD, and 1 for WLF and HHE (Table 4).

Six of the 192 QTL regions overlapped for 2 of the traits (Table 5): half of them involved DD and IH (chro-

Table 3. Difference in the observed frequency of lesions between the worst and best of the 5 groups of validation animals, based on $\mathrm{EBV}^{1}$

\begin{tabular}{lllll}
\hline Item & BLUP & GBLUP & BayesC & SSGBLUP \\
\hline Digital dermatitis & $0.07^{*}$ & $0.08^{* *}$ & $0.09^{* *}$ & $0.08^{* *}$ \\
Heel horn erosion & 0.02 & $0.06 \dagger$ & $0.06 \dagger$ & $0.10^{* *}$ \\
Interdigital hyperplasia & $0.03^{*}$ & $0.05^{* *}$ & $0.04^{* *}$ & $0.04^{* *}$ \\
Sole hemorrhage circumscribed & 0.03 & 0.03 & 0.04 & 0.03 \\
Sole hemorrhage diffused & $0.13^{* *}$ & $0.11^{* *}$ & $0.07^{*}$ & $0.13^{* * * *}$ \\
Sole ulcer & $0.05^{* *}$ & $0.07^{* * * *}$ & $0.06^{* * * *}$ & $0.08^{* * * *}$ \\
White line fissure & $0.05 \dagger$ & $0.07^{* *}$ & $0.07^{* *}$ & $0.09^{* * * *}$ \\
\hline
\end{tabular}

${ }^{1}$ GBLUP $=$ genomic BLUP; SSGBLUP $=$ single-step genomic BLUP.

Significance levels based on a $t$-test: $\dagger P \leq 0.10,{ }^{*} P \leq 0.05$, ${ }^{* *} P \leq 0.01$, **** $P<0.0001$. 
Table 4. Major evidence (2logBF $\geq 10$ ) QTL detected and number of annotated genes close to their regions

\begin{tabular}{|c|c|c|c|c|c|c|}
\hline Trait $^{1}$ & Chromosome & $\begin{array}{l}\text { Window } \\
\text { start (MB) }\end{array}$ & $\begin{array}{l}\text { Window } \\
\text { end (MB) }\end{array}$ & $\begin{array}{l}\text { Position of } \\
\text { peak (MB) }\end{array}$ & $\begin{array}{l}2 \log B F^{2} \\
\text { at peak }\end{array}$ & $\begin{array}{c}\text { No. of } \\
\text { annotated } \\
\text { genes }\end{array}$ \\
\hline DD & 2 & 83.349 & 83.349 & 83.349 & 11.5 & 1 \\
\hline DD & 5 & 20.607 & 20.607 & 20.607 & 12.2 & 5 \\
\hline HHE & 29 & 1.348 & 1.348 & 1.348 & 10.2 & 18 \\
\hline $\mathrm{IH}$ & 3 & 15.600 & 15.600 & 15.600 & 10.4 & 38 \\
\hline $\mathrm{IH}$ & 6 & 96.070 & 96.070 & 96.070 & 10.8 & 5 \\
\hline $\mathrm{IH}$ & 8 & 98.811 & 98.848 & 98.811 & 10.3 & 3 \\
\hline $\mathrm{IH}$ & 10 & 41.514 & 42.433 & 41.514 & 12.4 & 14 \\
\hline WLF & 6 & 87.022 & 88.111 & 88.111 & 11.9 & 27 \\
\hline
\end{tabular}

mosomes 1, 5, and 14), $1 \mathrm{DD}$ and WLF on chromosome 19, $1 \mathrm{DD}$ and SU on chromosome 20, and $1 \mathrm{IH}$ and WLF on chromosome 14. The QTL region common to $\mathrm{DD}$ and $\mathrm{IH}$ on chromosome 5 is also a major evidence QTL for DD.

A quite large number of genes were annotated on or close to QTL regions identified above (either major evidence QTL or QTL involved in 2 traits): 38 for the IH QTL on chromosome 3, 17 for a region on chromosome 14, overlapping for IH and WLF. Details for all QTL regions can be found in Appendix Table A2.

\section{DISCUSSION}

\section{Lesion Frequencies}

Lesion frequencies were generally similar in the whole population and in the genotyped population: genotyped cows were a representative subset of the population, with consistent lesion frequencies, although they tended to have slightly fewer lesions. The youngest genotyped individuals had in general lower lesion frequencies, which was expected because younger cows are less likely to develop a lesion and some lesions very rarely occur early in life. This difference in frequencies causes validation animals to be not representative of the whole population. However, young candidate bulls would be in a similar situation as their young daughters are less likely to develop lesions than older cows.

\section{Genomic Evaluation}

The development of genomic evaluations for claw health traits is still quite recent (Heringstad et al., 2018) and faces some specific challenges: generally low heritabilities, high costs of phenotyping, a low number of offspring with phenotype per sire and hence low accuracies of sire phenotypes (usually deregressed proofs or pre-adjusted performances of their daughters). Genomic evaluations are promising for the evaluation of claw health traits and can perform quite well. Given the challenges offered by these traits, it is necessary to assess the usefulness of a genomic evaluation in a new population and female reference populations are of major interest. Although the number of studies focusing on genomic evaluation of health traits is growing, few of them specifically focus on lameness (Parker Gaddis et al., 2014; McNeel et al., 2017), and only recently, some have focused on claw health (Dhakal et al., 2015; Ødegård et al., 2015; Stoop et al., 2015; Chesnais et al., 2016; Jamrozic et al., 2017; Naderi et al., 2018).

The definitions of evaluated traits vary widely among authors and they have various ways of estimating the accuracy of genomic evaluation approaches. Com-

Table 5. QTL regions common to 2 of the traits

\begin{tabular}{lcccrrrr}
\hline $\begin{array}{l}\text { Trait } \\
\text { involved }\end{array}$ & Chromosome & Start $^{2}$ & End $^{2}$ & $\begin{array}{c}\text { Position } \\
\text { of peak } \\
\text { trait 1 (MB) }\end{array}$ & $\begin{array}{c}\text { Position } \\
\text { of peak } \\
\text { trait 2 (MB) }\end{array}$ & $\begin{array}{c}\text { 2logBF } \\
\text { peak } \\
\text { trait 1 }\end{array}$ & $\begin{array}{c}\text { 2logBF } \\
\text { peak } \\
\text { trait 2 }\end{array}$ \\
\hline DD-IH & 1 & 33.674 & 33.934 & 33.674 & 33.674 & 6.1 & 6.5 \\
DD-IH & 5 & 20.607 & 20.607 & 20.607 & 20.607 & 12.2 & 7.6 \\
DD-IH & 14 & 77.222 & 77.222 & 77.222 & 77.222 & 7.3 & 8.6 \\
DD-WLF & 19 & 30.413 & 30.479 & 30.341 & 30.479 & 6.8 & 7.0 \\
DD-SU & 20 & 47.920 & 47.920 & 47.920 & 48.511 & 6.9 & 9.1 \\
IH-WLF & 14 & 2.755 & 3.841 & 2.827 & 3.030 & 9.0 & 6.6 \\
\hline
\end{tabular}

${ }^{1} \mathrm{DD}=$ digital dermatitis; $\mathrm{IH}=$ interdigital hyperplasia; $\mathrm{SU}=$ sole ulcer; $\mathrm{WLF}=$ white line fissure.

${ }^{2}$ Beginning and end of the overlapping region for traits 1 and 2 .

${ }^{3} \mathrm{BF}=$ Bayes factor. 
pared with Naderi et al. (2018), where the definition of accuracy is similar to ours, our estimates are low. However, their design of the validation population was quite different, as they chose the optimal percentage of sick cows to allocate to the validation population to maximize accuracy, when in our case we focused on young individuals. Furthermore, they grouped various individual lesions under a general "claw disorders" trait where we evaluated individual lesion traits. Grouping the individual lesions under a single trait was used in most genomic studies focusing on claw health (Dhakal et al., 2015; Ødegård et al., 2015; Stoop et al., 2015; Chesnais et al., 2016), whereas in France it was decided to run genomic evaluation on individual lesion traits and then to summarize them in 2 selection indexes for selection purposes. These selection indexes are resistance to noninfectious lesions (10\% SHC, 10\% SHD, $40 \% \mathrm{SU}, 40 \% \mathrm{WLF}$ ) and resistance to infectious lesions ( $50 \% \mathrm{DD}, 25 \% \mathrm{HHE}, 25 \% \mathrm{IH}$ ), weighted according to their importance for farmers. The very nature of the response variable (YD calculated from an animal linear model on binomial traits with low heritabilities and only one record per animal) might also be responsible for the generally low accuracies we observed, as the response variable has a low precision.

The standard errors of validation accuracy and bias estimates were high due to the moderate size of the female validation population and the low heritabilities of the traits considered. Generally, accuracy differences were not significant between evaluation approaches, genomic approaches did not necessarily perform better than regular BLUP, and ranking among BLUP, single, and 2-step evaluation approaches varied depending on the trait. However, when differences between evaluations were significant, SSGBLUP was the approach with the highest accuracy. Similar studies (Ødegård et al., 2015; Dhakal et al., 2015; Stoop et al., 2015; Naderi et al., 2018) found that genomic approaches led to greater accuracies than pedigree approaches and concluded that SSGBLUP was the best approach. However, these studies did not provide the standard errors of accuracy estimates or significance levels of differences in accuracies. Our study confirms that SSGBLUP is a relevant approach when a small female reference population is available, heritabilities are low, and only a small proportion of the individuals are genotyped. This is due to the exhaustive inclusion of information and transfer of information from genotyped to nongenotyped individuals.

Given the low accuracies observed, increasing the reference population should be a priority. As data collection is still quite recent in France, the number of phenotypes and genotypes is increasing rapidly and accuracy gains are expected in the months to come. Fur- thermore, as the number of records collected increases, the percentage of cows with repeated claw trimmings also increases. Therefore, the evaluation model should be extended to include a permanent environment effect to take into account repeated records. This should also increase accuracy, as genotyped animals will have more accurate phenotypes.

As accuracies were low, 2 alternative validation procedures were considered to get a clearer view of the ranking of validation animals. This particular type of validation, although less precise, allows a reduction of the noise due to the low accuracy of the response variable for validation and is regularly used for the validation of health traits, with generally satisfying results (Malchiodi et al., 2015; McNeel et al., 2017). These alternative validation procedures allowed for a better understanding of the ranking of validation animals and confirmed that genomic evaluation of claw health traits can be used to generate genetic gain in our population. The ranking of validation animals was also consistent with the differences in frequency observed between the best and worst classes of validation individuals. Furthermore, the frequency differences confirmed that, despite the low estimates of heritabilities, variability for claw health traits exists in the population and selection is possible. Finally, this part of the study also confirmed that SSGBLUP appears to be the best approach among those studied as it allowed for the best segregation of healthy and affected cows.

\section{QTL Detection}

Detection of QTL revealed a large number of QTL with strong evidence, including 13 that were either major evidence QTL or QTL that were common for 2 of the traits, indicating they are less likely to be false positives. Seven of the 8 major QTL regions were QTL for an infectious traits and 3 of the 6 common QTL regions involved 2 infectious traits. One of these regions was a major QTL for DD and a region common for DD and IH. The common QTL regions for DD and IH might come from a common genetic background, as the genetic correlation between these traits is high $(0.76$, Croué et al., 2017) but could also be related to other factors. Interdigital hyperplasia can for instance be a consequence of an infection from DD or DD can occur on an IH, as the freshly grown flesh is more susceptible to infection and might be recorded as a DD even if it is not on its usual spot. Most of these 13 QTL regions overlapped or were close to several genes. This highlights the fact that resistance to claw lesions is related to a high number of genes with small effects, but also seems to be particularly driven by some specific chromosomic regions. It confirms that there is a genetic 
determinism of claw health traits and that cows can be selected for specific resistance to claw lesions.

Some QTL detection studies focused on claw lesions specifically (Scholey et al., 2012; Swalve et al., 2014; van der Spek et al., 2015; Wu et al., 2016; Naderi et al., 2018) and others on feet and leg conformation (Buitenhuis et al., 2007; Cole et al., 2011; Wu et al., 2013). Once again, a large diversity of approaches and QTL selection criteria were used. However, 25 out of the 192 strong evidence QTL identified in our study were identical or close (less than $1 \mathrm{MB}$ apart) to a QTL reported in one of those studies. Five of them were located on chromosome 10 and 3 on chromosome 22 . It would be interesting to further investigate the QTL detected in our study with a GWAS and compare the 2 studies. More specifically, given the data structure (low percentage of genotyped individuals) and the relatively low accuracy of pre-adjusted performances, using a SSGWAS to combine pedigree, phenotype, and genotype information for QTL detection might be an effective approach.

The QTL regions identified for major evidence QTL and QTL common for 2 of the traits were generally dense in genes (145 annotated genes were located less than $500 \mathrm{~kb}$ apart from one of the QTL regions; among them 118 were located close to QTL regions for an infectious trait). Twenty-four of these genes, located on chromosomes $3,5,6,8,10,14$, and 19 had functions associated with the immune system, making them potential candidate genes for resistance to claw lesions; 20 of them were close to a QTL region for an infectious trait. In particular, $E P Y C$, on chromosome 5 $(20,909,663-20,950,211)$, close to a QTL identified for DD and IH, was associated with osteoarthritis in mice and, more interestingly, to a form of Ehlers-Danlos syndrome in cattle, which causes soft and hyper-extensible skin, delayed wound healing, and skin fragility (Tajima et al., 1999). This might explain a higher susceptibility to DD and a longer time before healing.

Except for $E P Y C$, no other obvious candidate genes were observed for resistance to claw lesions. However, a few promising QTL (either with major evidence or overlapping for 2 of the traits) exist, and including them in a genetic evaluation model, either through a marker-assisted approach or weighting SNP depending on their influence on the traits, might allow for extra gains in accuracy.

\section{CONCLUSIONS}

Genomic selection is a promising tool to increase resistance to claw lesions in French Holstein cows. Although validation accuracies were quite low and heritabilities are very low, groups of best and worst validation animals are well discriminated and enough variability is present for genetic improvement to occur. The QTL detection study also confirms the existence of a genetic determinism of these traits. Several levers can be used to increase the accuracy of the genomic evaluation of claw heath: an obvious increase of the reference population, the use of a SSGBLUP approach, and the inclusion of specific QTL in the evaluation model. A lot of genes are located in the QTL, including some potential candidate genes that could be further investigated; $E P Y C$, located on chromosome 5, is the most promising one.

\section{ACKNOWLEDGMENTS}

This study is part of the Genosante project, led by EVOLUTION (Noyal-sur-Vilaine, France) and managed by Maëlle Phlippe (EVOLUTION, France). The authors thank all of their colleagues of the mixed technology unit eBIS (Jouy-en-Josas, France) who contributed to this study for their continuous help and support, the claw trimmers for their work on collecting the data, Francois Guillaume (EVOLUTION, France), Luc Manciaux (Bretagne Conseil Elevage Ouest, France), Jean Bernard Davière (CLASEL, France), Luc Voidey (Elistest, France), Denis Boichon (Auriva, France) for granting access to the phenotypes and managing the database, and APIS-GENE (Paris, France) for financial support (partly through the POD2 project).

\section{REFERENCES}

Aguilar, I., I. Misztal, D. L. Johnson, A. Legarra, S. Tsuruta, and T. J. Lawlor. 2010. Hot topic: A unified approach to utilize phenotypic, full pedigree, and genomic information for genetic evaluation of Holstein final score. J. Dairy Sci. 93:743-752. https://doi.org/10 $.3168 /$ jds.2009-2730.

Bruijnis, M. R., B. Beerda, H. Hogeveen, and E. Stassen. 2012. Assessing the welfare impact of foot disorders in dairy cattle by a modeling approach. Animal 6:962-970. https://doi.org/10.1017/ S1751731111002606.

Bruijnis, M. R., H. Hogeveen, and E. N. Stassen. 2010. Assessing economic consequences of foot disorders in dairy cattle using a dynamic stochastic simulation model. J. Dairy Sci. 93:2419-2432. https://doi.org/10.3168/jds.2009-2721.

Buitenhuis, A. J., M. S. Lund, J. R. Thomasen, B. Thomsen, V. Nielsen, C. Bendixen, and B. Guldbrandtsen. 2007. Detection of quantitative trait loci affecting lameness and leg conformation traits in Danish Holstein cattle. J. Dairy Sci. 90:472-481. https:// doi.org/10.3168/jds.S0022-0302(07)72649-8.

Charfeddine, N., and M. A. Pérez-Cabal. 2017. Effect of claw disorders on milk production, fertility, and longevity, and their economic impact in Spanish Holstein cows. J. Dairy Sci. 100:653-665. https: //doi.org/10.3168/jds.2016-11434.

Chesnais, J. P., T. A. Cooper, G. R. Wiggans, M. Sargolzaei, J. E. Pryce, and F. Miglior. 2016. Using genomics to enhance selection of novel traits in North American dairy cattle. J. Dairy Sci. 99:2413-2427. https://doi.org/10.3168/jds.2015-9970.

Christensen, O. F., and M. Lund. 2010. Genomic prediction when some animals are not genotyped. Genet. Sel. Evol. 42:2-8. https:/ /doi.org/10.1186/1297-9686-42-2. 
Cole, J. B., G. Wiggans, L. Ma, T. Sonstegard, T. Lawlor, B. Crooker, C. Tassell, J. Yang, S. Wang, L. Matukumalli, and Y. Da. 2011. Genome-wide association analysis of thirty one production, health, reproduction and body conformation traits in contemporary U.S. Holstein cows. BMC Genomics 12:408. https://doi.org/10.1186/ 1471-2164-12-408.

Croué, I., F. Fikse, K. Johansson, E. Carlén, G. Thomas, H. Leclerc, and V. Ducrocq. 2017. Genetic evaluation of claw health traits accounting for potential preselection of cows to be trimmed. J. Dairy Sci. 100:8197-8204. https://doi.org/10.3168/jds.2017-13002.

Dhakal, K., F. Tiezzi, J. S. Clay, and C. Maltecca. 2015. Short communication: Genomic selection for hoof lesions in first-parity US Holsteins. J. Dairy Sci. 98:3502-3507. https://doi.org/10.3168/jds .2014-8830.

Enting, H., D. Kooij, A. A. Dijkhuizen, R. B. M. Huirne, and E. N. Noordhuizen-Stassen. 1997. Economic losses due to clinical lameness in dairy cattle. Livest. Prod. Sci. 49:259-267. https://doi.org/ 10.1016/S0301-6226(97)00051-1.

EVOLUTION. 2017. Dossier de presser GENOSANTE: Innover pour la santé des bovins laitiers. EVOLUTION, Noyal-sur-Vilaine, France.

France Génétique Elevage. 2013. Projet PARABOV - Bilan de la collecte. Accessed Oct. 2018. http://idele.fr/no_cache/recherche/ publication/idelesolr/recommends/projet-parabov-2011-2012 .html.

Gernand, E., P. Rehbein, U. U. Borstel, and S. König. 2012. Incidences of and genetic parameters for mastitis, claw disorders, and common health traits recorded in dairy cattle contract herds. J. Dairy Sci. 95:2144-2156. https://doi.org/10.3168/jds.2011-4812.

Habier, D., R. Fernando, K. Kizilkaya, and D. Garrick. 2011. Extension of the Bayesian alphabet for genomic selection. BMC Bioinformatics 12:186. https://doi.org/10.1186/1471-2105-12-186.

Heringstad, B., C. Egger-Danner, N. Charfeddine, J. E. Pryce, K. F. Stock, J. Kofler, A. M. Sogstad, M. Holzhauer, A. Fiedler, K. Müller, P. Nielsen, G. Thomas, N. Gengler, G. de Jong, C. Odegard, F. Malchiodi, F. Miglior, M. Alsaaod, and J. B. Cole. 2018. Invited review: Genetics and claw health: Opportunities to enhance claw health by genetic selection. J. Dairy Sci. 101:4801-4821. https:// doi.org/10.3168/jds.2017-13531.

International Committee for Animal Recording. 2015. ICAR Claw Health Atlas. Accessed May 17, 2016. http://www.icar.org/ documents/icar_claw_health_atlas.pdf.

Jamrozic, J., G. J. Kistemaker, B. J. van Doormaal, F. Malchiodi, and F. Miglior. 2017. Genetic Evaluation for Digital Dermatitis. Accessed Jun. 20, 2018. https://www.cdn.ca/Articles/ GEBAPR2017/Janusz\%20DCBGC\%20Digital\%20Dermatitis\%20 Report\%20-\%20March\%202017.pdf.

Johansson, K., J.-A. Eriksson, U. Sander Nielsen, J. Pösö, and G. Aamand. 2011. Genetic evaluation of claw health in Denmark, Finland and Sweden. Int. Bull. 44:224-228.

Kass, R. E., and A. E. Raftery. 1995. Bayes factors. J. Am. Stat. Assoc. 90:773-795.

Legarra, A., P. Croiseau, M. Sanchez, S. Teyssèdre, G. Sallé, S. Allais, S. Fritz, C. Moreno, A. Ricard, and J.-M. Elsen. 2015. A comparison of methods for whole-genome QTL mapping using dense markers in four livestock species. Genet. Sel. Evol. 47:6. https:// doi.org/10.1186/s12711-015-0087-7.

Legarra, A., A. Ricard, and O. Filangi. 2014. GS3, Genomic selection - Gibbs sampling - Gauss Seidel (and BayesC $\pi$ ). Accessed Aug. 5, 2015. http://snp.toulouse.inra.fr/ alegarra/.

Malchiodi, F., A. Koeck, N. Chapinal, M. Sargolzaei, A. Fleming, D. F. Kelton, F. S. Schenkel, and F. Miglior. 2015. Genetic analyses of hoof lesions in Canadian Holsteins using an alternative contemporary group. Int. Bull. 49.

McNeel, A. K., B. Reiter, D. Weigel, J. Osterstock, and F. Croce. 2017. Validation of genomic predictions for wellness traits in US Holstein cows. J. Dairy Sci. 100:9115-9124. https://doi.org/10 $.3168 /$ jds.2016-12323.

Michenet, A., M. Barbat, R. Saintilan, E. Venot, and F. Phocas. 2016. Detection of quantitative trait loci for maternal traits using high- density genotypes of Blonde d'Aquitaine beef cattle. BMC Genet. 17:88. https://doi.org/10.1186/s12863-016-0397-y.

Misztal, I. 2008. Reliable computing in estimation of variance components. J. Anim. Breed Genet. 125:363-370. https://doi.org/10 .1111/j.1439-0388.2008.00774.x.

Misztal, I., A. Legarra, and I. Aguilar. 2009. Computing procedures for genetic evaluation including phenotypic, full pedigree, and genomic information. J. Dairy Sci. 92:4648-4655. https://doi.org/10 $.3168 /$ jds.2009-2064.

Naderi, S., M. Bohlouli, T. Yin, and S. König. 2018. Genomic breeding values, SNP effects and gene identification for disease traits in cow training sets. Anim. Genet. 49:178-192. https://doi.org/10 .1111 /age.12661.

Ødegård, C., M. Svendsen, and B. Heringstad. 2015. Foot and leg conformation traits have a small effect on genomic predictions of claw disorders in Norwegian Red cows. J. Dairy Sci. 98:4139-4147. https://doi.org/10.3168/jds.2014-9186.

Parker Gaddis, K. L., J. B. Cole, J. S. Clay, and C. Maltecca. 2014. Genomic selection for producer-recorded health event data in US dairy cattle. J. Dairy Sci. 97:3190-3199. https://doi.org/10.3168/ jds.2013-7543.

Scholey, R. A., R. Blowey, R. Murray, R. Smith, J. Cameron, J. Massey, W. Ollier, and S. Carter. 2012. Investigating host genetic factors in bovine digital dermatitis. Vet. Rec. 171:624. https://doi .org/10.1136/vr.101251.

Schurink, A., L. Janss, and H. Heuven. 2012. Bayesian variable selection to identify QTL affecting a simulated quantitative trait. BMC Proc. 6:S8. https://doi.org/10.1186/1753-6561-6-S2-S8.

Stoop, W., G. de Jong, M. van Pelt, and C. van der Linder. 2010. Implementation of a claw health index in the Netherlands. Interbull Bull. 42:95-99.

Stoop, W. M., C. Schrooten, J. Vermeer, and G. de Jong. 2015. Validation and implementation of new genomic traits in The Netherlands: Lactose, urea, calf survival, ketosis, conception rate, heifer feritility and AMS traits. Interbull Bull. 49:6-9.

Swalve, H. H., C. Floren, M. Wensch-Dorendorf, K. Schöpke, R. Pijl, K. Wimmers, and B. Brenig. 2014. A study based on records taken at time of hoof trimming reveals a strong association between the IQ motif-containing GTPase-activating protein 1 (IQGAP1) gene and sole hemorrhage in Holstein cattle. J. Dairy Sci. 97:507-519. https://doi.org/10.3168/jds.2013-6997.

Tajima, M., S. Miyake, K. Takehana, A. Kobayashi, O. Yamato, and Y. Maede. 1999. Gene defect of dermatan sulfate proteoglycan of cattle affected with a variant form of Ehlers-Danlos syndrome. J. Vet. Intern. Med. 13:202-205. https://doi.org/10.1111/j.1939-1676 .1999.tb02179.x.

van der Spek, D., J. A. M. Arendonk, and H. Bovenhuis. 2015. Genome-wide association study for claw disorders and trimming status in dairy cattle. J. Dairy Sci. 98:1286-1295. https://doi.org/10 $.3168 /$ jds.2014-8302.

van der Waaij, E. H., M. Holzhauer, E. Ellen, C. Kamphuis, and G. Jong. 2005. Genetic parameters for claw disorders in Dutch dairy cattle and correlations with conformation traits. J. Dairy Sci. 88:3672-3678. https://doi.org/10.3168/jds.S0022-0302(05)73053 -8 .

VanRaden, P. M. 2008. Efficient methods to compute genomic predictions. J. Dairy Sci. 91:4414-4423. https://doi.org/10.3168/jds .2007-0980.

Wakefield, J. 2009. Bayes factors for genome-wide association studies: Comparison with P-values. Genet. Epidemiol. 33:79-86. https:// doi.org/10.1002/gepi.20359.

Wu, X., M. Fang, L. Liu, S. Wang, J. Liu, X. Ding, S. Zhang, Q. Zhang, Y. Zhang, L. Qiao, M. Lund, G. Su, and D. Sun. 2013. Genome wide association studies for body conformation traits in the Chinese Holstein cattle population. BMC Genomics 14:897. https: //doi.org/10.1186/1471-2164-14-897.

Wu, X., B. Guldbrandtsen, M. Lund, and G. Sahana. 2016. Association analysis for feet and legs disorders with whole-genome sequence variants in 3 dairy cattle breeds. J. Dairy Sci. 99:7221-7231. https: //doi.org/10.3168/jds.2015-10705. 
APPENDIX

Table A1. Full list of identified QTL ${ }^{1}$

\begin{tabular}{|c|c|c|c|c|c|}
\hline Trait & Chromosome & Window start (MB) & Window end (MB) & Position of peak (MB) & $2 \log B F$ at peak ${ }^{2}$ \\
\hline DD & 1 & 33.6739 & 33.9338 & 33.6739 & 6.1 \\
\hline $\mathrm{DD}$ & 1 & 67.4442 & 67.4917 & 67.4917 & 6.5 \\
\hline $\mathrm{IH}$ & 1 & 95.3436 & 95.3949 & 95.3436 & 6 \\
\hline $\mathrm{SU}$ & 1 & 109.707 & 111.06 & 110.721 & 7.7 \\
\hline WLF & 1 & 128.373 & 128.373 & 128.373 & 6.5 \\
\hline $\mathrm{SHC}$ & 1 & 136.868 & 136.868 & 136.868 & 6.1 \\
\hline SHC & 1 & 158.162 & 158.162 & 158.162 & 7.4 \\
\hline $\mathrm{SHC}$ & 2 & 3.15199 & 3.67329 & 3.4078 & 6.8 \\
\hline WLF & 2 & 57.4811 & 57.7272 & 57.4811 & 6.4 \\
\hline HHE & 2 & 67.5752 & 67.7661 & 67.7661 & 7.1 \\
\hline $\mathrm{DD}$ & 2 & 83.3491 & 83.3491 & 83.3491 & 11.5 \\
\hline DD & 3 & 9.97418 & 10.6404 & 10.4625 & 6.8 \\
\hline $\mathrm{IH}$ & 3 & 15.6001 & 15.6001 & 15.6001 & 10.4 \\
\hline $\mathrm{SU}$ & 3 & 15.728 & 16.2657 & 16.1521 & 7.2 \\
\hline HHE & 3 & 44.9015 & 44.9015 & 44.9015 & 6.2 \\
\hline SU & 3 & 98.3162 & 98.5216 & 98.4121 & 6 \\
\hline $\mathrm{IH}$ & 3 & 100.127 & 101.165 & 100.229 & 6 \\
\hline HHE & 3 & 109.016 & 109.494 & 109.016 & 7.2 \\
\hline DD & 3 & 113.354 & 114.284 & 114.284 & 6.2 \\
\hline HHE & 4 & 1.9444 & 1.9444 & 1.9444 & 7.5 \\
\hline IH & 4 & 7.33837 & 7.82371 & 7.33837 & 6.8 \\
\hline HHE & 4 & 17.5563 & 17.5563 & 17.5563 & 6.2 \\
\hline SU & 4 & 28.1172 & 28.6216 & 28.6216 & 7.7 \\
\hline WLF & 4 & 67.6545 & 67.7728 & 67.7728 & 8.9 \\
\hline $\mathrm{DD}$ & 4 & 73.8615 & 73.8615 & 73.8615 & 6.1 \\
\hline WLF & 6 & 87.0221 & 88.1112 & 88.1112 & 11.9 \\
\hline SU & 6 & 88.4813 & 89.049 & 88.8223 & 6.1 \\
\hline $\mathrm{IH}$ & 6 & 96.0704 & 96.0704 & 96.0704 & 10.8 \\
\hline $\mathrm{IH}$ & 6 & 103.752 & 104.197 & 104.197 & 7.1 \\
\hline WLF & 7 & 0.86388 & 1.65698 & 1.65698 & 6.1 \\
\hline DD & 7 & 17.404 & 17.404 & 17.404 & 7.4 \\
\hline SU & 7 & 36.555 & 36.555 & 36.555 & 6.4 \\
\hline $\mathrm{IH}$ & 7 & 53.3145 & 53.513 & 53.336 & 6.5 \\
\hline WLF & 7 & 56.3317 & 56.3317 & 56.3317 & 6.2 \\
\hline DD & 7 & 108.326 & 108.964 & 108.964 & 6.3 \\
\hline $\mathrm{SHC}$ & 7 & 109.596 & 109.634 & 109.596 & 6.9 \\
\hline $\mathrm{DD}$ & 8 & 1.76792 & 1.79445 & 1.79445 & 6.7 \\
\hline WLF & 8 & 6.31171 & 6.37288 & 6.37288 & 6.7 \\
\hline $\mathrm{HHE}$ & 8 & 30.2848 & 30.3206 & 30.3206 & 6.7 \\
\hline HHE & 8 & 34.5845 & 34.9476 & 34.9476 & 6 \\
\hline WLF & 8 & 36.4899 & 36.4899 & 36.4899 & 8.7 \\
\hline DD & 8 & 36.6419 & 37.1582 & 37.1566 & 7.4 \\
\hline IH & 8 & 71.6003 & 71.6003 & 71.6003 & 6.1 \\
\hline $\mathrm{IH}$ & 8 & 98.811 & 98.848 & 98.811 & 10.3 \\
\hline SHD & 8 & 102.859 & 103.61 & 103.484 & 7.5 \\
\hline
\end{tabular}


Table A1 (Continued). Full list of identified QTL ${ }^{1}$

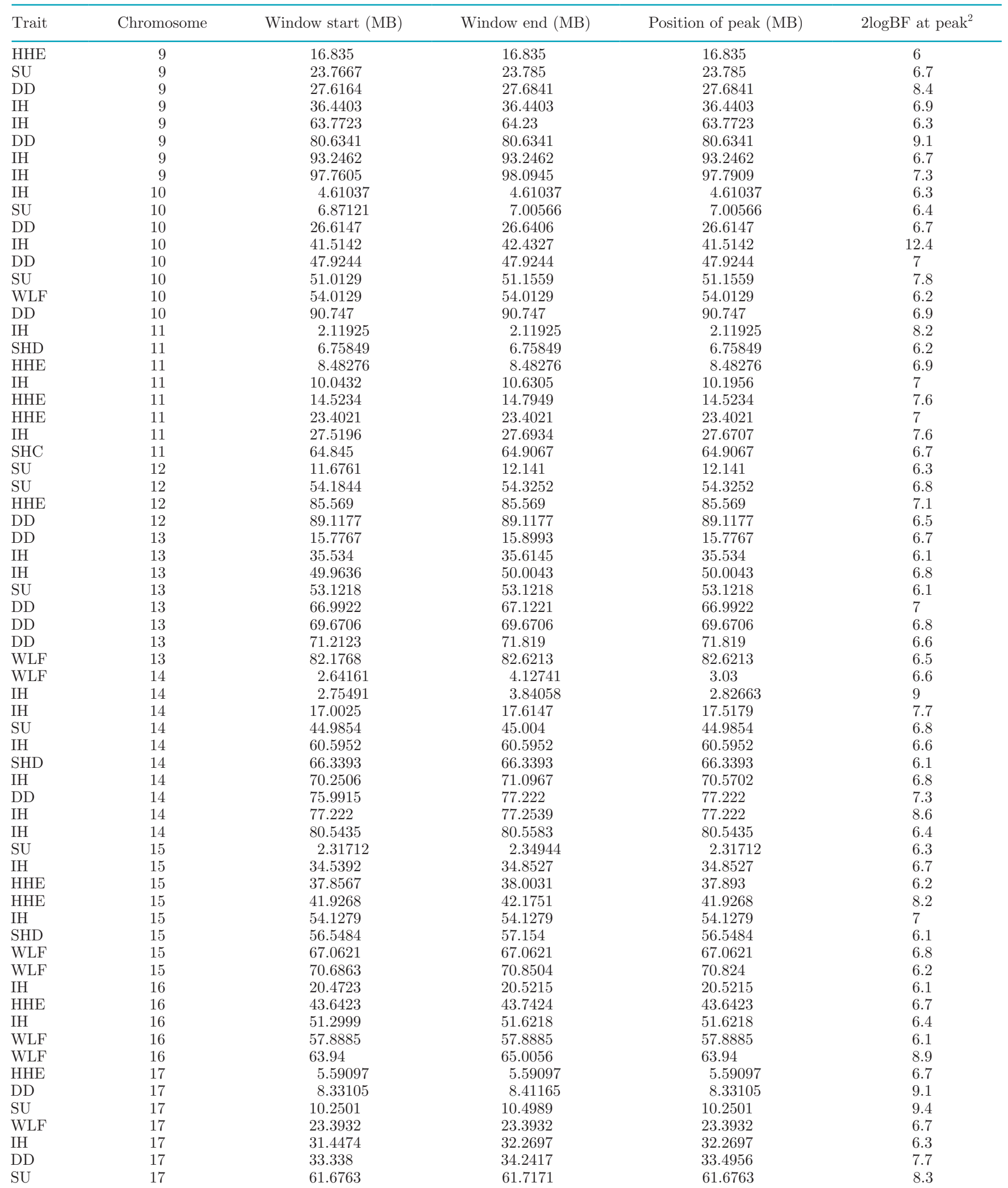


Table A1 (Continued). Full list of identified QTL ${ }^{1}$

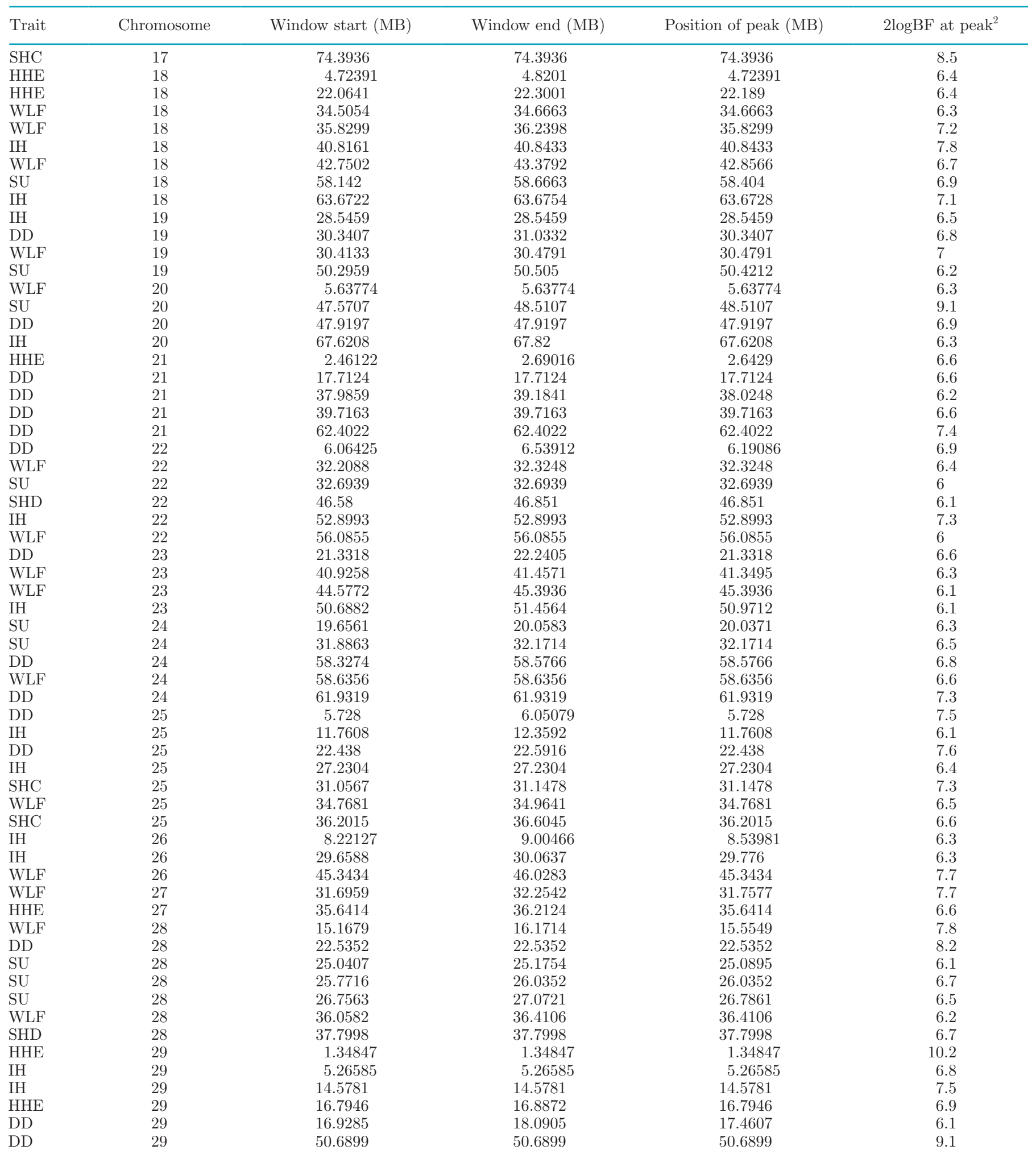

${ }^{1} \mathrm{SHC}=$ sole hemorrhage circumscribed; SHD = sole hemorrhage diffused; DD = digital dermatitis; HHE = heel horn erosion; IH = interdigital hyperplasia; $\mathrm{SU}=$ sole ulcer; $\mathrm{WLF}=$ white line fissure.

${ }^{2} \mathrm{BF}=$ Bayes factor. 
Table A2. Annotated genes on all major evidence QTL and QTL common for 2 traits; in bold: genes associated with immune system functions

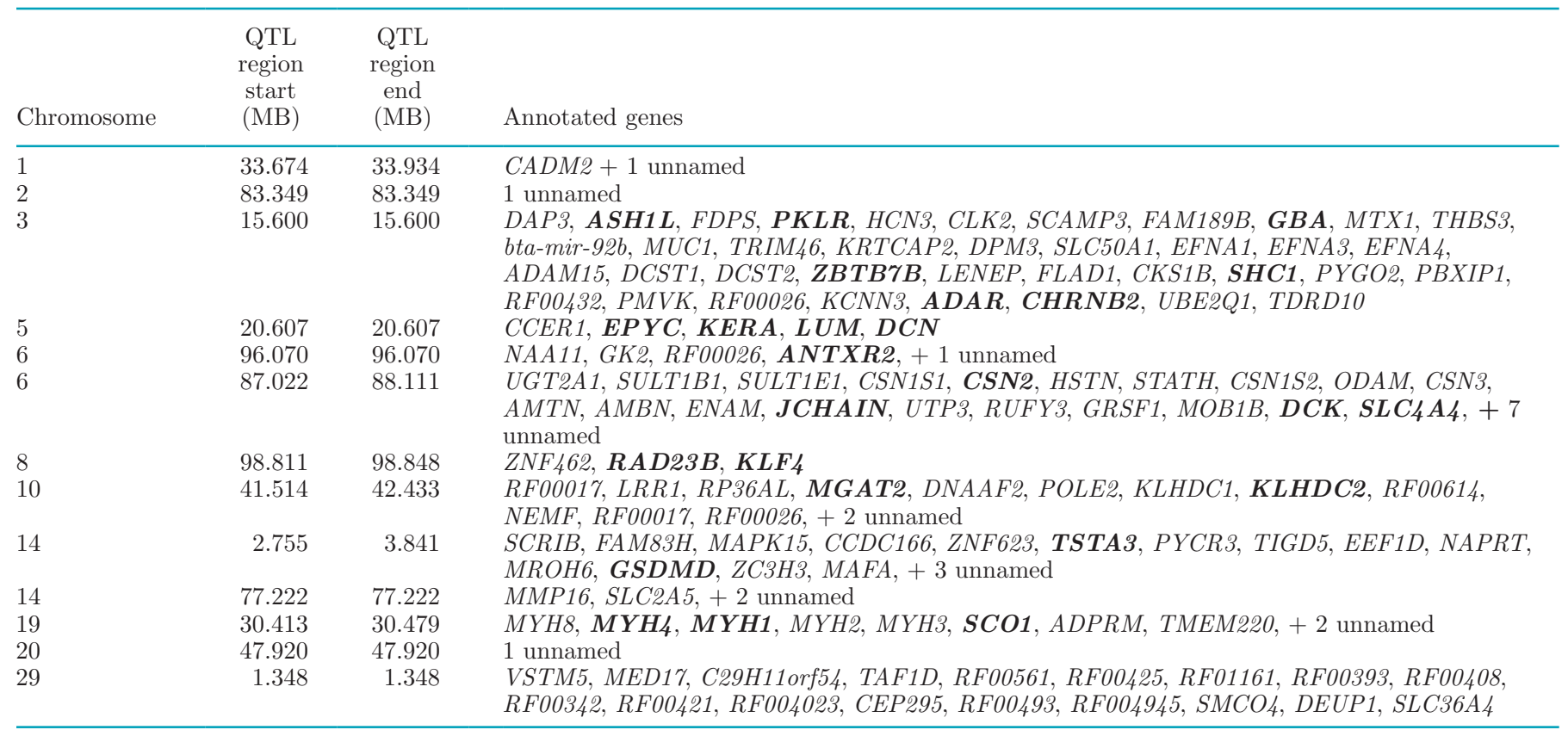

